العدد الحادي والأربعون

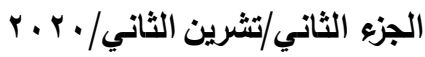

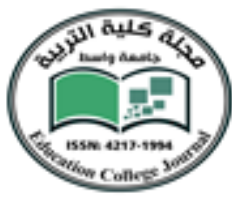

\title{
قصيدة النثر في العرلق فرج الحطّاب انموذجاً
}

أ.م.د. عباس اجريدي لفته

ونارة التربية /الكلية التربوية المفتوحة

hishamabbas362@gmail.com

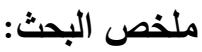

تُعدُّ قصبد النثر محل خلاف دائمًا، فبين مَنْ يؤيد رافعًا القبعة لهذه القصبدة، وبين آخر لايعترف بوجودها أصلاً، وبين هذا وذاك سارت الهوينا محرزة بعض القليل خصوصاً في البدايات الأولى؛ لكنها بمرور الأيام استطاعت أنْ تجد موطئ قدم في الساحة الثقافية. من خلال التوطئة لقصيدة النثر العراقية حصرًا، وجدنا أنها عمل فردي في بداية الأمر لم يشكل خطورة؛ ولكن سرعان ما اشتذ عودها

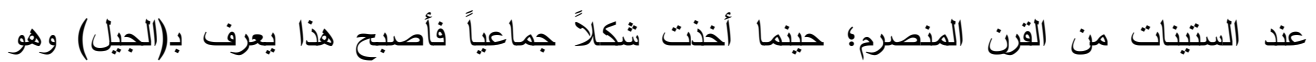
مصطلح يتفس رؤيته ورؤياه.

طرح فرج الحطّاب نفسه كمثقف في بداية الأمر وقبل أنْ يكون شاعراً؛ لهذا صقلت موهبته القراءاتُ المتتوعة فضلاً عن الوعي الذي تمتع به فكان أبو تمام والمتتبي وأبو العلاء قديماً والسياب وأدونيس مثلاً حديثًا له، وثَمَّة مسردُ من المؤلفات التي انتجها الحطّاب ذكرناها؛ تبدأ بسيول أليفة ولا تتنهي بسياسية الألم والمعنى. كانت أولى المجاميع (سيول أليفة) التي لها على المستوى الفني مخالفة

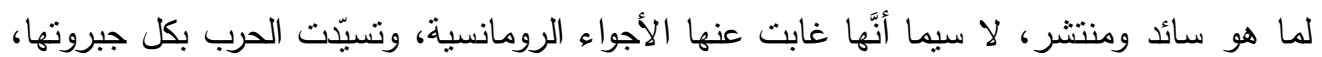
وثاني الموضوعات دون منازع هو الحصار لقد ظل الاثتان- الحرب والحصار - خير مثال لموضوعاتها.

أما فنية القصيدة لدى الحطّاب فسلطتُ الضوء عليها من خلال اللغة والصورة، فتمت اللغة وتفرعت الألفاظ التي شكلت قوة فاعلة مهيمنة، وأخرى ألفاظ عامية التي شكلت الكثير في مدونته الشعرية، ثم دراسة الأساليب الثعرية، وهي الومضة، واليومي، والمهمل، وكسر التوقع،

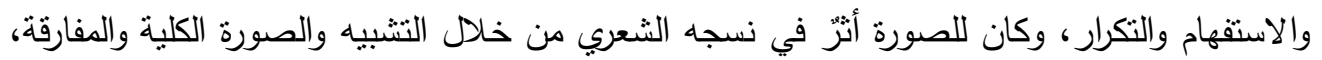
والاستعارة.

إنَّ الحطّاب كان أكثر تحديداً في الإفادة من الموروث العربي قديمه وحديثه، إضافة إلى إفادته من الأبب العالميّ. أما النتائج التي انتهيت إليها فقد بسطت القول فيها في خاتمة البحث. كلمات مفتاحية: قصيدة النثر فرج الحطّاب سيول أليفة يجر هدوءه بوقار 

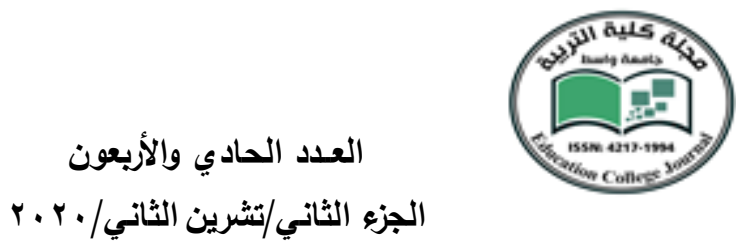

Abstract:

The prose poem is always a matter of dispute, as between those who support this poem, and others who do not recognize its existence at all, and thus, it began to develop slowly, especially in the early beginnings. However, over time, it was able to find a foothold in the cultural arena. Through the exclusive introduction to the Iraqi prose poem, we found that it was an individual work in the beginning which was not dangerous. Its return, however, quickly intensified in the 1960s, when it took a collective form, and this became known as "generation," a term that arose to importance.

Faraj al-Hattab presented himself as an intellectual in the beginning and before he was a poet. Therefore, his talent refined the various readings in addition to the awareness he enjoyed. Influenced by Abu Tammam, AlMutanabi, and Abu Al-Ala in the past, and Al-Sayyab and Adonis in the present, there is a bibliography of the books produced by Al-Hattab we mention. It begins with Domestic Torrents and ends with the Politics of Pain and Meaning. His collection Domestic Torrents (1996), was distinct on the artistic level as it was different to what was prevalent and widespread, especially as it lacked the romantic atmosphere, while it focused on the war and prevailed with all its might. The second focus in the collection is the economic sanctions and thus, both the war and sanctions remained the best examples of the main themes.

As for the artistic characteristics of the poem of al-Hattab, he sheds light on it through language and image, so that the language and expressions established a dominant effect and branched out to other colloquial expressions that were present a lot in his poetic works.

In this work, I studied the poetic methods, which are the flashing image, the daily life, the neglected subject, the shocking expectation, questioning and repetition, and the image had an effect on his poetic works through the use of simile, the overall image, the paradox, and the metaphor. Al-Hattab was more specific in making use of the ancient and modern Arab heritage, in addition to his benefit from international literature. As for the results that I concluded, they are explained in the conclusion of the research. 
العدد الحادي والأربعون

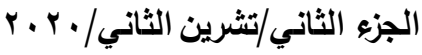

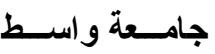

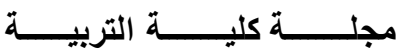

لقصيدة النثر الأولوية في قصب السبق من حيث الإهتمام المبكر سواء أكان معها أو ضدها،

فقد سارت بهدوء لاسيما في بداياتها التي لم تشكل نداً قوياً في الثقافة العراقية.

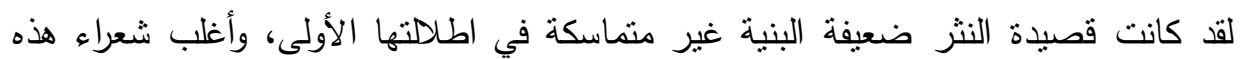
القصيدة آنذاك لا يعدونها هدفًا أو حلمًا يسعون اليه في إيجاد أرضهم الخصبة التي يستتبتون قصائدهم فيها، فكانت القصيدة العمودية هي المركز ولها الصدارة في الترتيب. وقد كان الزهاوي من الأوائل الذين مهدوا الطرقات كي يعبر الآخرون الجدد، التي أحوج ما يكونوا إلى نوع من المساعدة الشعرية، خصوصاً أنّ الزهاوي صاحب تجربة وشخصية نقافية؛ بل (كان شاعرًا عقليًا) (الخياط، A و (م، ص صاT) يتسيد الأجواء الضبابية في العراق لاسيما نظرته التجديدية في القصيدة، التي كما الشعر المرسل أثبه بالهواء يلعب في شباكها، ربّما ليستقبد منها المجدون بعد سنوات طوال. ولقد كان نذًا للزهاوي فيما طرح من أفكار ورؤى خصوصًا القافية، الرصافي الذي لا يمكن له له

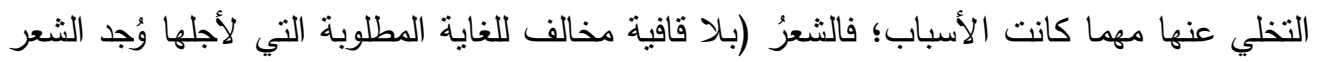
وهي الغناء) (الصكر، 99 (9م، ص. (1)، والملاحظ أنّ الرصافي واضح كل الوضوح فيما يخص قصيدة النثر، فهو لا يفضلها على الموروث الأدبي صاحبة الذوق الذي نرعرع فيه؛ لكن الرصافي برغم الحب الكبير للقافية يظل الجانب الخفي لقصيدة النثر هنا او هناك مخبوء في بعض قصائده. ومن التجارب الغنية في قصيدة النثر تجربة روفائيل بطي، فقد رافقت هذه القصيدة صدور ديوانه المستّى(الربيعيات)، وهي الخطوة الرائدة محتذيًا في هذا المجال أمين الربحاني الذي كان أكثر تفهمًا

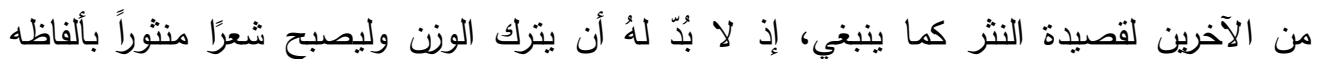
ومعانيه، لقد غادر القصيدة ذات البناء الهندسي وأصبح مشجعًا من الدرجة الأولى ألاّ وهو الريحاني بتاريخه الطويل ويرفده هذا التاريخ الأدبي بالدواوين الثعرية التي كانت شرارة مشعة في سماء بغداد من منل (هتاف الأودية) و (الريحانيات). لق سارت قصيدة النثز وأمامها عقبات كثيرة رغم أنها لم تلاق الثاعر الكبيرة الذي يأخذها إلى الى

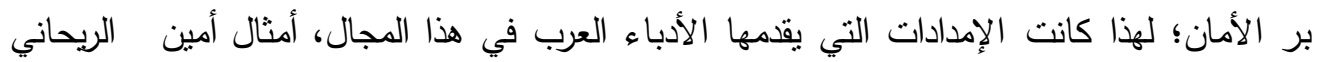
الذي كان هاربًا من ثلاث عبوديات (عبودية السياسة وعبودية الأدب وعبودية الطائفية) (اليوسفي،

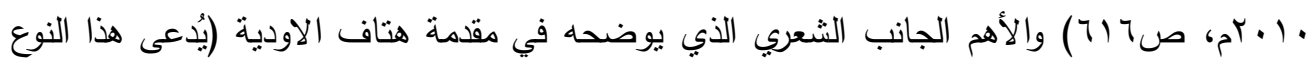
من الشعر الجديد بالفرنسية vers Libers وبالإنكليزية Free V) أبي الشعر الحر الطليق). وثانيهم جبران خليل جبران الذي عاصر الربحاني (تكمن أهميته في الدور الذي أسداهُ للآداب العربيّ عامة

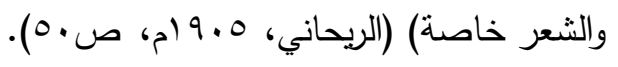


العدد الحادي والأربعون

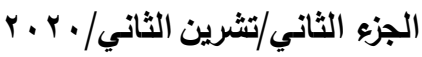

وإذا كان الريحاني قد عمد إلى (سبك الخيال الشعري بعبارات ممّا يتعوده العرب) (الريحاني، المصدر نفسه، صبrه)؛ فإنّ جبران قد أطلق (نيارًا من الغنائية الثعرية والعاطفية من الخيال الشعريّ الراقي عبر النثر) (محفوظ، بو9 (م، صبی1). وثالثهم الثاعر ميخائيل نعيمه في (همس الجفون) فضلاً عن كتابه (الغربال) الذي يعدُّ انطلاقة سريعة إلى القرّاء العرب، لاسيما آرائه الجديدة التي

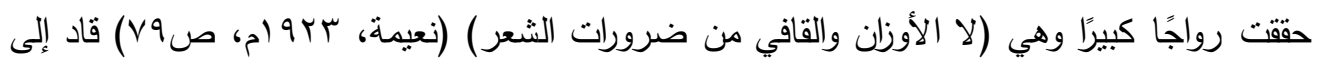
ذائقة جديدة في فهم الشعر وكان لمجلة الأديب دور فعال في توجيه الشعر (خلقت جواً مناسباً لظهور

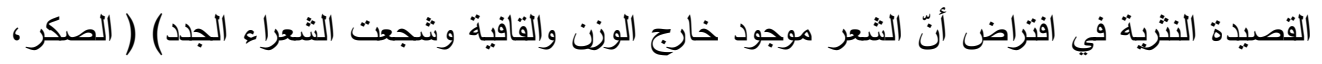
199(99 (1) (1) مما أعطى البذور الماء الكثيف كي يبث الثكل الجديد في الأديب القاص وإن كان ليس شاعراً آنذاك - عبد المجيد لطفي - حاول نشر أثعاره النثربة في مجلات حوت الكثير من نصوصه النثرية، وظلت لم تأخذ كفايتها من الترويج والإعلان حتى صدور ديوانه الأول المسمّى

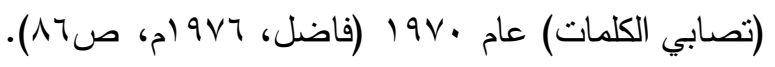
وإذا كانت تجارب قصيدة النثر خجولة في بداياتها بعض الشيء؛ فإنّ تجربة حسين مردان خرجت إلى الملأ دون وجل، فجاءت (الربيع والجوع) حاملة التحدي، كحال شعراء القصيدة، يحمون شق غبار السكون، واضافت المصطلح النقدي الذي سيكون شائعا وهو النثر المركز ، وان قلت الحدة تجاهه خصوصا أن مردان كان بودليري النزعة في الشعر والحياة. وتوالت دواوينه (الأرجوحة هادئة الجبال، وطراز خاص، وصور مرعبة، ونشيد الإنشاد). لقد كانت تجارب حسين مردان من التجارب المهمة، ويحق لنا أنْ نسميه الثاعر الثعبي من ذلك الوقت (قصائد عارية) وهو شاغل الناس وأضحت نصوصه مدار حديث الثارع. إنّ طفرة حسين مردان في قصيدة النثر ليست قليلة، وما قدم يعدُّ الأول في اصداره الدواوين المتلاحقة على (الربيع والجوع)؛ لكنها لم تأخذ السطوع والمكانة التي حازتها في الثعر خصوصًا أنّ تجربة الثعر الحر على أوجها في الصعود الشعري لكنّه يحفر في منطقته الخاصة.

وإذا اشتخل شعراء قصيدة النثر عربيًا في الخمسينات على نحو ما؛ إلاّ أنّهم ظلوا بعيدين عن التسمية هيّابين من الدخول في ملكوتها؛ ومن أبرز هؤلاء الشعراء توفيق صايغ ومحد الماغوط وجبرا إبراهيم جبرا وابراهيم شكر الله. فمثلاً توفيق صايغ ابتدأ في طرح مجامعيه الشعرية (ثلاثتن قصيدة) عام ؟1901، علمًا أنّها من قصيدة النثر ، لكنّه يتحفظ على التسميّة، وفي هذا الجانب يقول (في هذه الحركة الاكثر تجدداً أو الجديدة حقاً يمكن الاستغناء عن الوزن والقافية ووحدة البيت وموضوع الشعر الحديث المبكر ..بلغة مجازية بنوع جديد وداخلي ومتكامل من الايقاع والموسيقى برؤية جديدة للحياة 
العدد الحادي والأربعون

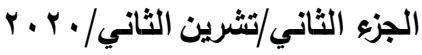

والوجود فقط نادرة على أن تفعل هذا على نحو ناجح ومقنع) (خوري، ا99 (م، ص (؛). وقد اضيف إلى ما ذُكر (أنّ مسميات مثل شعر النثر أو قصيدة النثر تبيّن أنّ عمله مازال غير مقبول ببساطة شعر) (خوري، المصدر نفسه، ص (§)، إنّ الذائقة العربية التي تربت قرون طويلة ليس باستطاعتها مفارقة المعهود من الشعر، لكن كل جديد منبوذ في بداية الأمر فكانت الخسائر المعنوية سرعان ما أخذت نتهاوى شيئًاً فشيئًاً. وإذا كان الثاعر العربي يخوض معركة حامية الوطيس عند أبوابها المتمثلة بالتسمية أعني (قصيدة النثر) فقد كنا بحاجة إلى شعراء يهذموا المفاهيم القديمة غير المقبولة، لهذا جاء أدونيس وأنسي الحاج ويوسف الخال. لا نقول إنهم هادمون القديم، فهم حملوا في نصوصهم الثيء الجديد الذي لا يفارق نسق القصيدة العربية برمتها، وإنما انصب اهتمامهم على تجديد القصيدة في وقت كانت بحاجة إلبه. كان العالم يشهد نظورات خطيرة وحرجة، وفي الوقت نفسه كان لا بذَّ من متابعة الواقع وقراءته بأكثر من رؤى؛ وبالرغم من ان هؤلاء الشعراء كان لهم (أصدقاء قلائل وأعداء كثيرون) (جبرا، • 19 (، صه • (1)؛ لكنهم كتبوا النص الشعريّ وفي داخلهم إيمانًا مطلقاً فشاعر (الوزن يقبل قواعد السلف ويتبناها بينما شاعر النثر متمرد رافض فهو ليس تلميذ؛ بل خالق وسيد) (أدونيس، • 97 (، ص0 ) وهو يرفع قصيدة النثر لأول مرة إلى الواجهة دون خوف أو وجل. وكذللك فعل

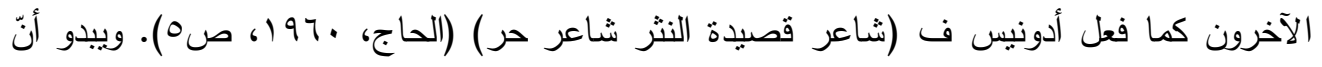
صدور مجلة شعر عام $190 V$ ساعد على تمهيد الأرض الصالحة وأضحت انطلاقة القصيدة في الستينات انطلاقة حقيقية بعد توافر سبل الانتشار والثيوع. في العراق، وفي مرحلة الستينات كان هناك أكثر من شاعر ، وكان من بين الأكثر تميّزاً فاضل العزاوي، وسركون بولص، ومؤيد الراوي، وجان دمو، وصدلاح فائق؛ فهؤلاء الثعراء لأول مرةٍ شكّلوا كتلة شعرية أو جماعة، كما انبنقت (جماعة كركوك) التي لعبت دورًا في (ارساء قصيدة النثر في

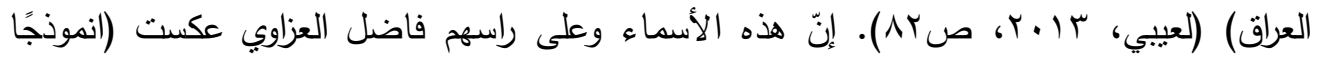

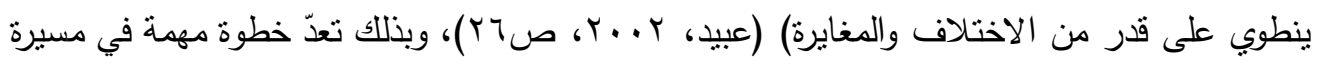
القصبدة.

وكان لمجلة الكلمة اسهامها في مد قصيدة النثر بالأسماء الجديدة من (شعراء السبعينات)، وإن كانت التسمية عالقة كما يراها بعض النقاد في (جيل ما بعد الستينات)، وأغلب الظن يعني شعراء

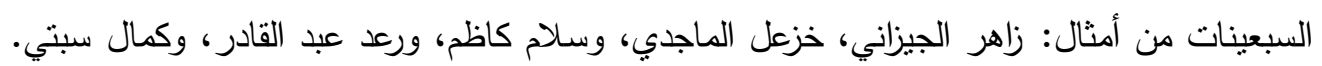


العدد الحادي والأربعون

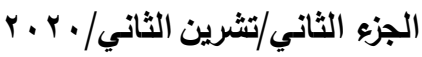

فقد وجد هؤلاء الشعراء أنفسهم يكتبون (شعرًا مملوءاً بالأحلام ومصنوعاً من أسنة المخيلة) (الجيزاني وكاظم، 7191(، ص99ץ)، هذا ما قاله زاهر الجيزاني وهو أحد الشعراء الكبار في الجيل. إنّ أصحاب هذا الجيل ذو (ثقافة ووعي جيدين فضلاً عن مَنْ قادوا كانوا من أصحاب المواهب

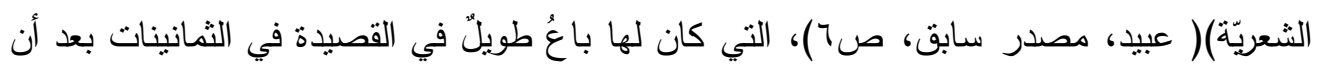
دار الوجه السبعيني يجد الحرب اشتعلت أوارها فولد جيل في ظل ثماني سنوات (نما وتطور في

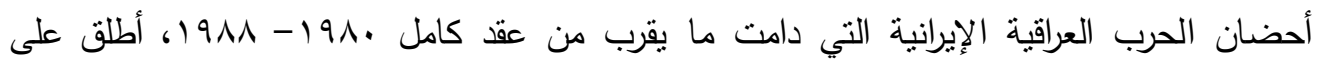
نفسه جيل الثمانينات) ( الجيزاني وكاظم، المصدر السابق، صی^ץ)، جيل الحرب والفقدان والخسائر؛ فخرجت أسماء جديدة في سماء القصيدة: محمد جاسم مظلوم، ومحمد تركي، وباسم المرعبي، وخالد جابر يوسف، ومنذر عبد الحر، وطالب عبد العزيز ، وعبد الزهرة زكي، ورعد فاضل، وغيرهم الكثير. في فترة التسعينات، كان السؤال الأهم، كيف يمكن أن تكتب قصيدة والجوع يحاصرك من كل

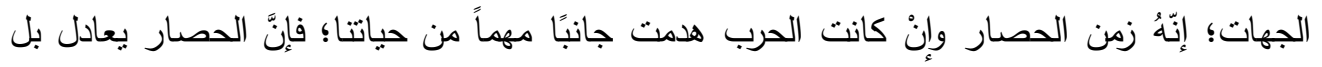
يتقوق بحروبه الاقتصادية والاجتماعية والثقافية أمام الساحة الشعرية. فشعراء التسعينات (ليسوا شعراء فقط بل محاربونَ أيضًا، شعراء يقفون في خنادق الثعر يواجهون سيولاً من الغزاة... الحصار

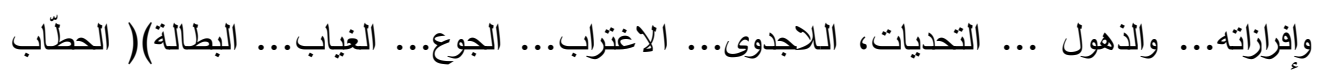

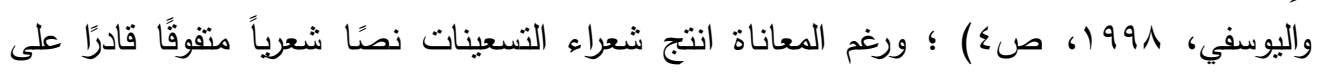
الابداع، فانتشرت بين أوساطهم ثقافة إصدار الدواوين بالاستتساخ منل علامتي الفارقة لسلمان داود محمد، وسيول أليفة لفرج الحطّاب، وصعادات لجمال علي الحلاق، وخطر لمحمد الحمراني، وربما الخرائط لأحمد الثيخ علي، واليوسيفيات لعباس اليوسفي، وسعادات سيئة الصيت لجمال جاسم أمين، وخطر، وموسى لحسين علي يونس، ومروق لسلام دواي... وهلم جرا. كانت القصيدة العراقية متجدة في كل الأزمنة يذهب جيل وفي جعبته يترك الكثير من الفراغات للجيل الثاني، لا نقول إنّ فلانًا أو ثلة من الشعراء قد صنعت ما عجز الآخرون من تدونيه.

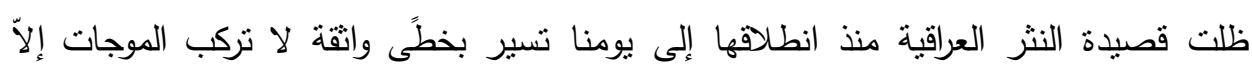
الضئيل منها فهي متجدة على الدوام ترفض الوقوف في مكان واحد بعد أن نفضه الآخرون؛ هكذا هي منطورة في أمسها وغدها ويومها دائماً تفكر بالآتي والمجهول لعله يخبئ ما عجز الآخرون من الوصول إليه، وسنحاول هنا الثقرب من أعمال الثاعر فرج الحطّاب بوصفه أحد الثعراء التسعينيين 
العدد الحادي والأربعون

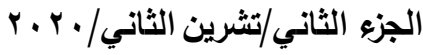

قبل الاخول في فضاءات النص:

بمكننا أنْ نقولَ إنَّ الثاعر فرج الحطّاب يعدّ من الأسماء ذات الأهمية في القصيدة التسعينية

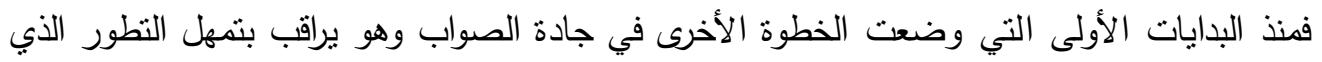
وصلته القصيدة، وكان يعي مقدار ما انجزته القصيدة العربية من انجاز هائل على المستويات كافة،

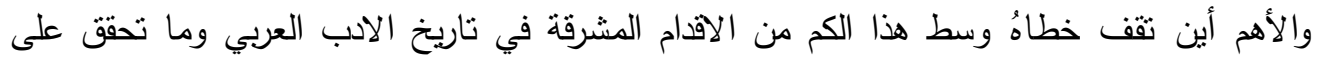

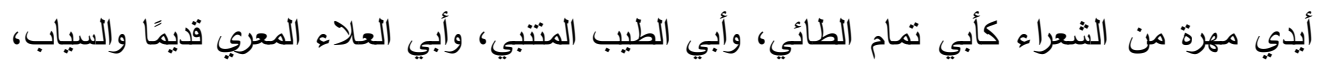

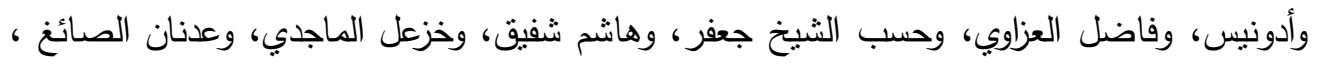

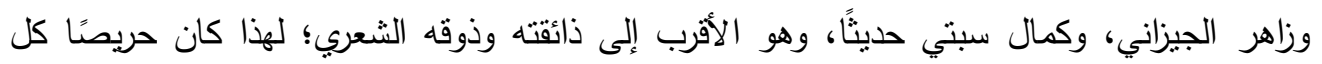

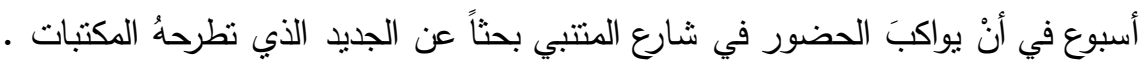

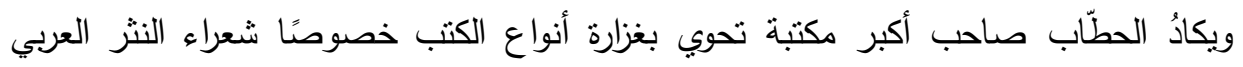

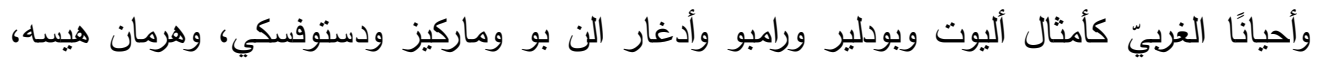

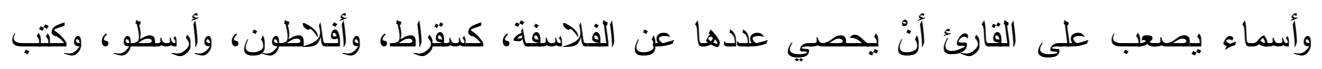

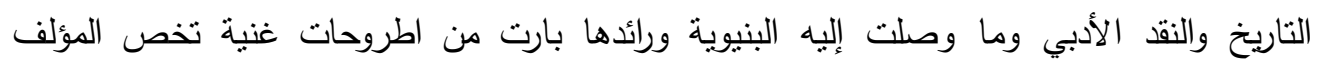

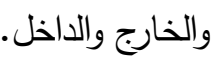

إنّ النقافة التي يتمتع بها الثاعر فرج الحطّاب جعلته من أبرز النقاد الثباب الذي تصدى في

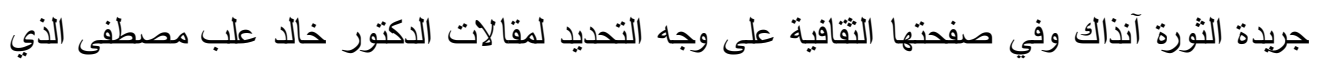

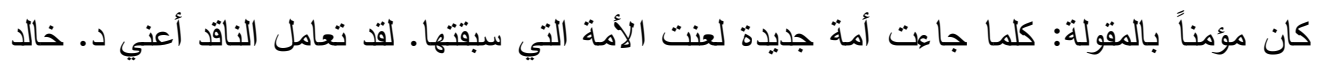

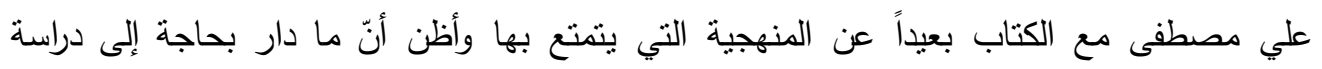

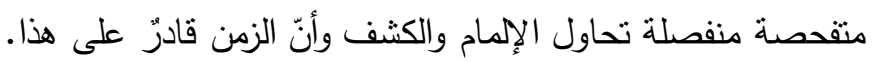

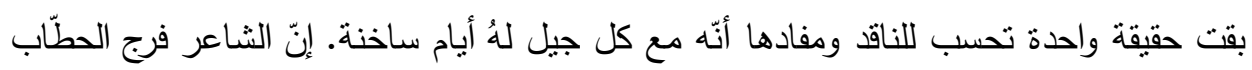

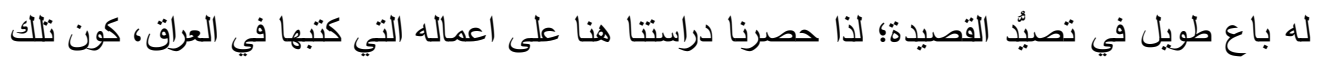

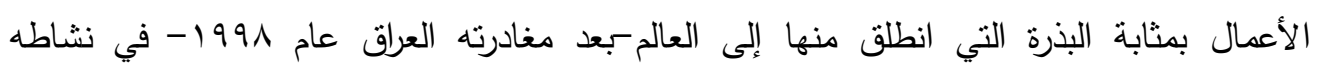

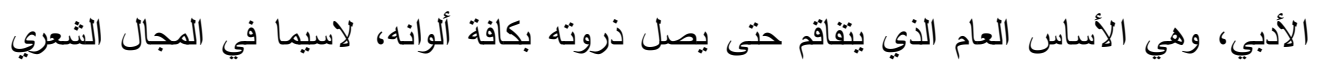

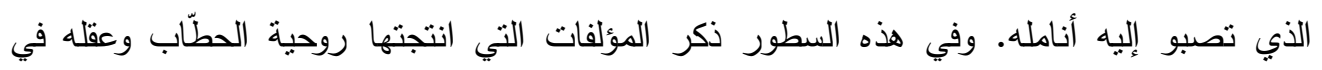
مسيرته الأدبية: 
العدد الحادي والأربعون

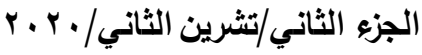

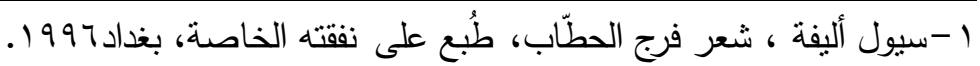

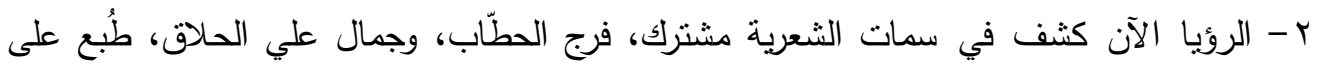

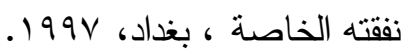

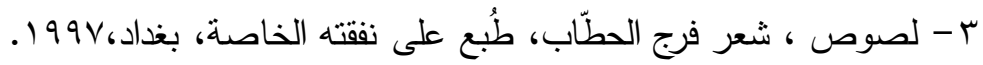
ع - الشعر العراقي الآن ، فرج الحطّّب، وعباس اليوسفي، طبع على نفقته الخاصة، 1991 ـ

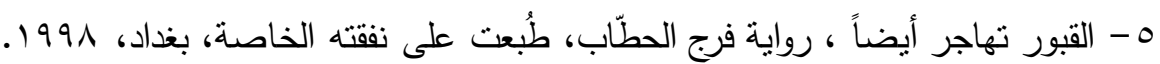
7 - هواء قلق، شعر، فرج الحطّباب، دار ألواح، مدربد، 1999 1.

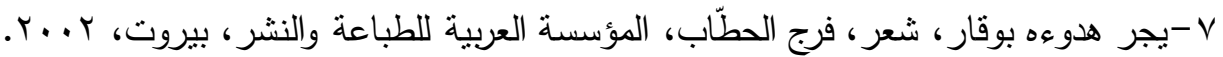
1 - سياسية الألم والمعنى، طقوس عاشوراء وزيارة الأربعين بالعراق، سلسلة دراسات فكرية في جامعة

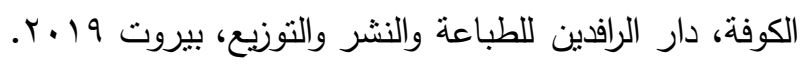

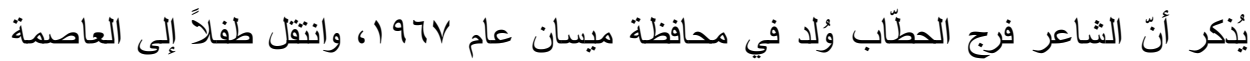

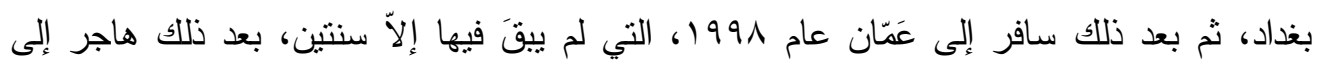

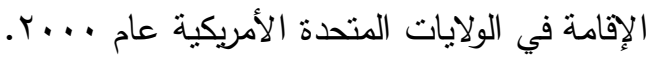
حصل الثاعر على البكالوريوس والماجستير والدكتوراه فضلاً عن سكنه في ولاية أريزونا ويعمل مدرسًا في جامعنها. سيول أليفة، بواكير أولى وأخيرة: تُعدّ سيول أليفة من المجاميع الأولى التي كان لها الحظوة والاهتمام من لذُن أصحاب القلم الذين يؤسسون إذ لم نقل للقادم من النشاط الأدبيّ، وأحيانًا يبشرون بالأصوات الواعدة التي لها حضورها في خربطة الإبداع. لقد جاءت سيول اليفة وإن منأخرة نوعاً ما؛ إلاًّ إنها جاءت ناضجة وبطريقة الاستتساخ، كأغلب المجاميع التسعينية التي يقوم أصحابها بطبعها على نفقتهم الخاصة. لقد كانت (سيول أليفة) مخالفة لما هو سائد ومنتشر حيث غالباً ما يسيطر الجو الرومانسي على أغلب الشعراء ومَنْ يطالعُ المجموعة سيجد ان القسم الأعظم منها تغيب عنه الأجواء الرومانسية كما هو منوافر في جوانب المجموعة: ان (الصباحية البهية، تطاردني دائماً مكتظة باحتضان آخر الثهود المخبئين في عنابر الانتظار 
العدد الحادي والأربعون

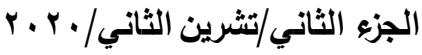

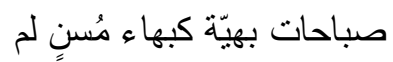

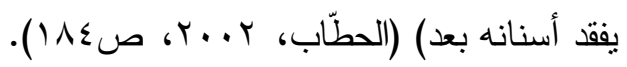

يلاحظ على المجموعة خلوها من الجو الرومانسيّ؛ ريّا نتيجة طبيعية لبلد خارج من حربين طاحنتين لم يشها منلمها في العصر الحديث، فبعد (اجتيازنا لكابوس الحرب الاولى ها نحن نعيش

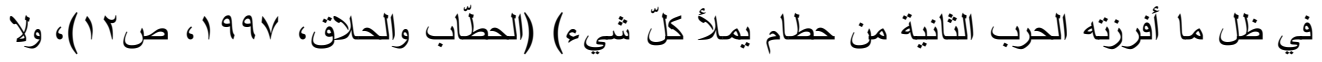

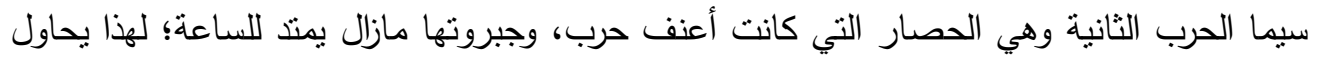
الحطّاب أن يحط بمساحة آمنة خالية من الدم والوشاية والقهر :

$$
\text { الآخرون وحدهُ نادما على شيء، }
$$

يشيّعون أفراحي بصدت يتساقط خلف

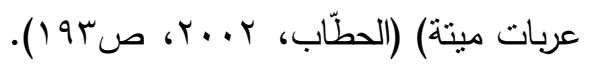

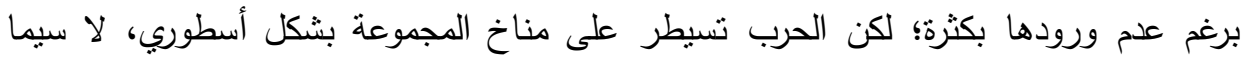

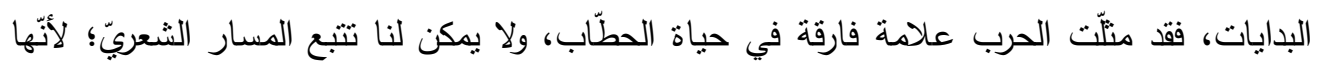

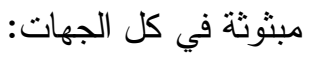
(خارجون من بطون التوابيت ومن جحور ابن آوى لمابن خارجون من شقوق الصخور ومن قبور لاكتها ألسنة الماكينات

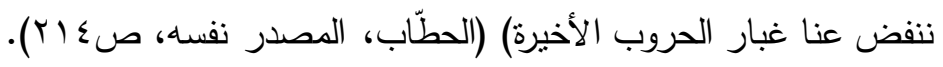

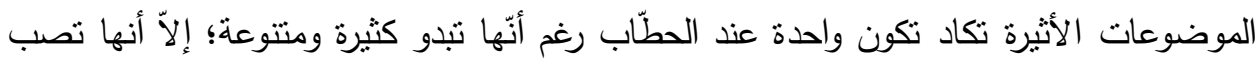

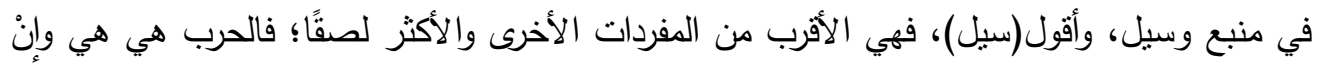

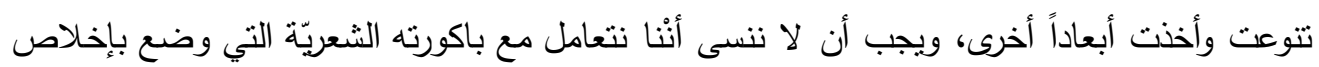

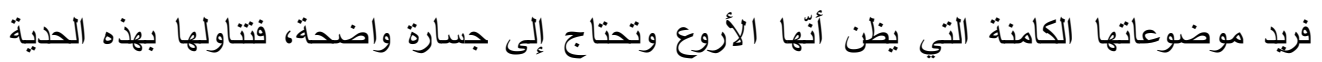
والجرأة والثجاعة في ذلك الوقت الحرج: 
العدد الحادي والأربعون

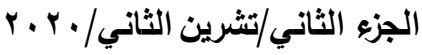

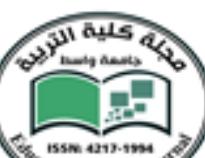

on Colless

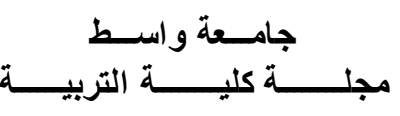

(الغيوم التي تملأ رأسي

سوف تمطر أفكاراً عظبمة

أو ثرثرات تافهة كثرثرات العجائز

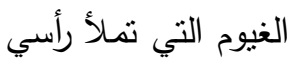

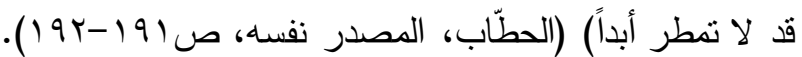

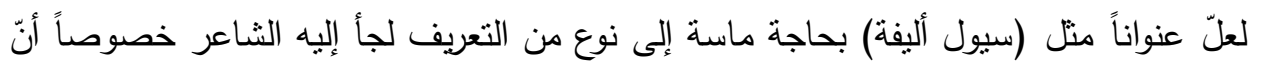
عنوان ديوانه (يجر هدوءه بوقار) والذي ضم مجاميعه الشعرية الأربعة، قد استقاهُ من مجموعته الأولى فصرنا أمام (سيول أليفة... يجر هدوءه بوقار). إنّ نهاية المجموعة تشي بنوع من الحكمة بعد

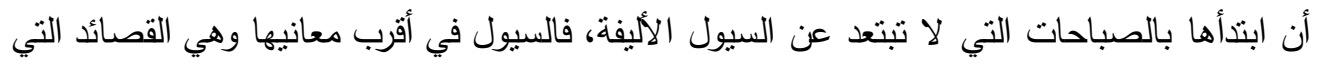
وضعها عنواناً لمجموعته تعدُّ ناجحة قياساً إلى عنوان جيله: (طبول للرقص، طبول للحزن،

$$
\text { وطبول بلا معنى، }
$$

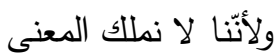
فإننا نملك القدرة على تأوبله هكذا علّمتنا أيامنا الباردة

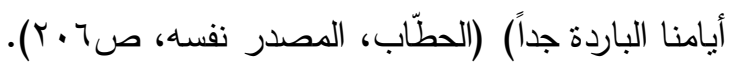
إنّ بواكير الحطّاب يصح أنْ نطلق عليها مجازاً لا تحمل من البواكير إلاّ الاسم فقط فالذي يخوض في النصوص سيجد نفسه أمام قاموسٍ من التأويلات.

\section{فنية القصبدة لاى فرج الحطّاب:}

لا يجرؤ الشاعر من طرح موضوعاته دون عدة مناسبة ونعني بهذه العدة هي اللغة، والصورة والموسيقى؛ وإن تقرعت، لكنها أشبه بالثالوت الذي سارت عليه القصيدة، فإذا كانت قد فقدت أحد العناصر أو خيل لبعضهم أنّها فاقدة وأغلب الظن؛ بل الظّن كله مشبعة حتى آخر رمق في أوصالها. إنّ اللغة الشعرية في كل جيل لها الأولويّة في اهتمام الشاعر؛ وإنْ كان مسلحاً بقسط وافرٍ من الألفاظ غير المستهكة أو المكررة تتهض من الركام اليوميّ؛ لأنّه (يفهم لغته ويُحملها كلَّ أثقاله النفسية والروحية) (الخوري، بדو1، ص.11)، فمن خلالها استطاع الثاعر من تفريغ الالآم والمعاناة التي كلما تزداد ثرونه اللغوية كانت هي الأكثر في (إطلاق الإمكانات السحرية الكامنة في 
العدد الحادي والأربعون

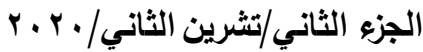

الكلمات) (ماثيسون، 1970، ص9119)؛ لهذا عدّت الألفاظ في تجربة الحطّاب محطة لا يمكن إلاّ الوقوف عندها بوصفها أيقونات صلدة مشاكسة. لقد تشكلت هذه الألفاظ أو بعضها في نسيج التجربة الشعرية وهي: الحروب، الأصدقاء،

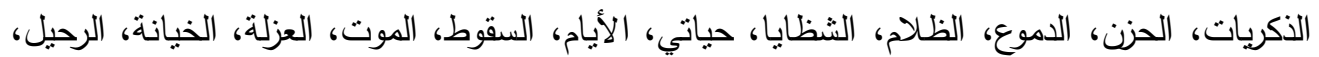
الجنود، المسرات، الألم، الوصايا، الريح، الرؤوس. ومن بين النصوص نقرأ:

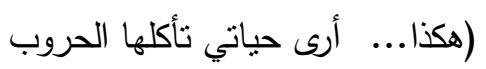
إنني الآن أشمها فقط ولا أعيشها أبحث عنها ولا أمارسها كذلك رأيتُ جثث الاصدقاء ولث املثهاء أو ما تبقى من ذكرياتهم

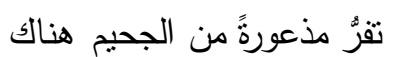

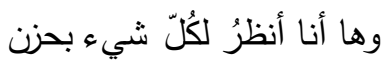

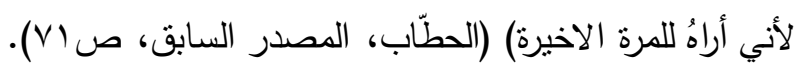

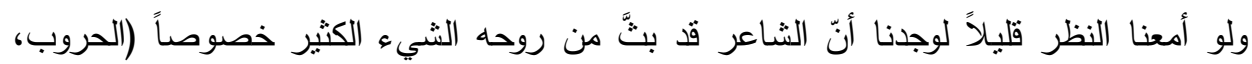

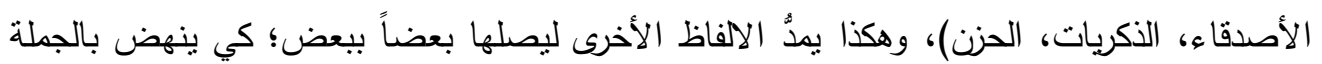
الشعرية. فلو أخذنا مفردة(الاصدقاء) على سبيل المثال؛ نجدها جاءت بدلالات تفارق الدلالة المعهودة التي نامت طويلاً في ذاكرتتا: (رقيقون وحين أصافحُ أيديهج تتحول إلى قنفذ لسانهم الذي يُسقط العسل

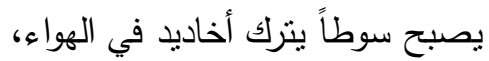
ونُدباً تنشطرُ

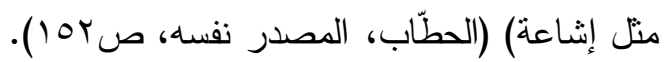
ونجدُ ميزةً مضافة في نص الحطّاب وهي ورود حزمة من الالفاظ العامية نستحق الوقوف عندها

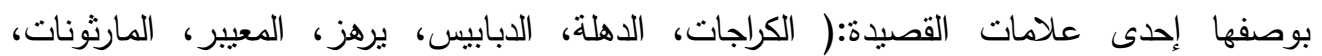


العدد الحادي والأربعون

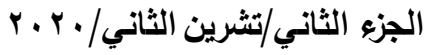

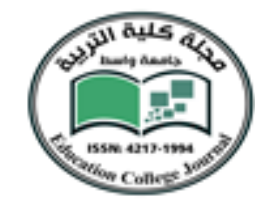

الطناطل، العنافيش، الحرفش، الأيونات السبورات، النهش، المساحي، مروحة، نرمس، نلطم)، وهناك ألفاظ غزبرة في مدونة الحطّاب يتقاسمها الشعراء في نصوصهم، وهم: جبران خليل جبران، والزهاوي، والرصافي، والريحاني، والسياب، وهلمّ جرا. إنّ اللغة الثعربة بحاجةٍ إلى أن (يكتب الثاعر كما يتكلم؛ بل يتكلم كما يكتب... تصبح اللغة جزءاً

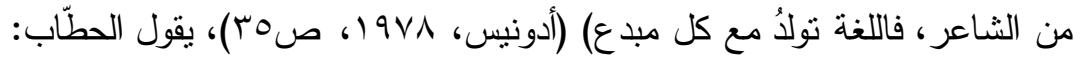
(نركب مشاحيف منقوبة ونحلم بالنجاة

نُمجدُ مستتقعات أفراحنا نَرمس في بركَ الثَك ولا ننتظر اليقين.... - الين مسحوبين من آخر أسناننا إلى أول ملصق يذكرنا بالافتراس

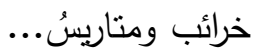

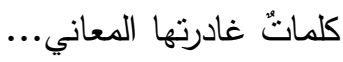
أسماؤنا التي ترن تتاكل ومسراتتا تلطعُ على التتاوب) (الحطّاب، 997 (، ص707-07). فالثاعر في هذا النص يحتقي بثلاث كلمات عامية (مشاحيف، نرمس، نلطُ)؛ مدّا أعطى قيمةً

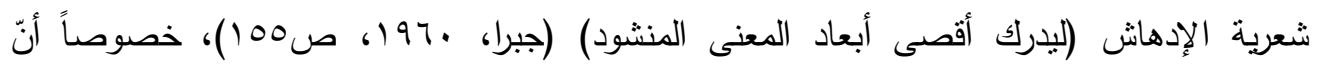
(مشاحيف مثقوبة/ مستتقعات أفراحنا/ نرمس في برك الثك/ مسراتتا تلطم) وكلها جاءت في غير المعنى التي وضعت للهُ.

شكلت الجملة الشعرية مهيمناً أسلوبياً في تجربة الحطّاب؛ بل إنّا فارقت كثيراً الشعريات المستهلكة المكررة وراحت تبحث عن كل ما هو إيجابي وغير مطروح في الساحة الثعرية؛ إذ نسعى في تشكيلها على تثوير الادهاث بكل تفاصيله داخل النواة المرّكزة في القصيدة.

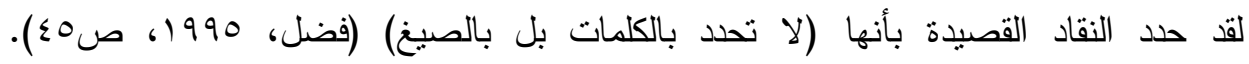

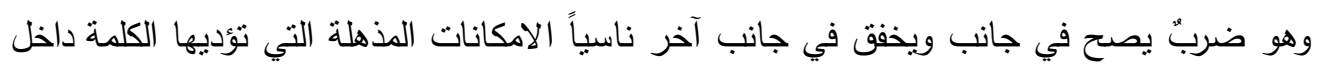

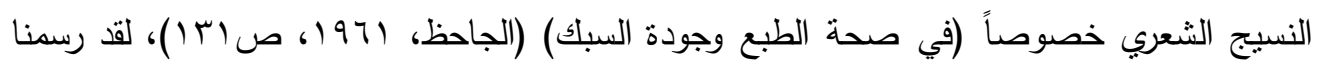
حدود الجملة الشعرية لدى الحطّاب، وفيما يأتي: الومضة/ اليومي والمهمل/ كسر التوقع/ الاستقهام/ التكرار • وسنحاول وبشيء من الايجاز الوقوف عندها حصراً، وعلى النحو الآتي: 
العدد الحادي والأربعون

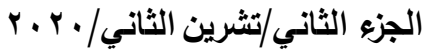

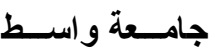

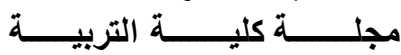

الومضة:

شاعت في قصيدة التسعينات الومضة عند الأوساط الأدبية، وقد بسمّيها بعضهم اللقطة، أو اللمحة أو المشهد، لكنّها الأقرب والأنسب من باقي التسميات، ومّنْ يراجع (يجر وفارهُ بهدوء)؛ سيجد حتماً

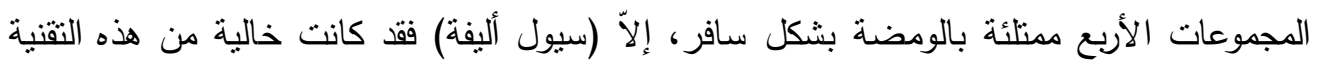

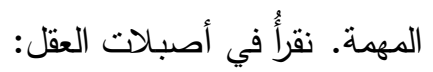
(رأسي مازال يؤلمني

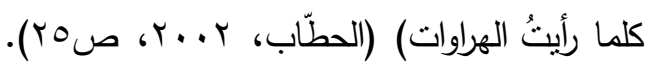
سيطرت الومضة بشكل كبير رغم قلة الألفاظ، غير انها استطاعت أنْ تتهض بالجملة الشعربة إلى أقصى درجات الوعي المتمتلة بـ (الهراوات) التي تشي بفقدان الحرية والطمأنينة. ويقول أيضًا:

أُدّلّكُ أفكاري وأملؤها بالحلم) (الحطّاب، المصدر نفسه، ص (ـ ارئ ). لقد ساعدت الومضة بانتشال الفيض الثعري من الغوص بعيداً لتصل بها بوساطة (أدلّك) إلى الحلم عبر مسارات نتظظر من لا يجيء حتى اضحت وسيلة للمعرفة ؛ فالحلم حسب الرمزيون

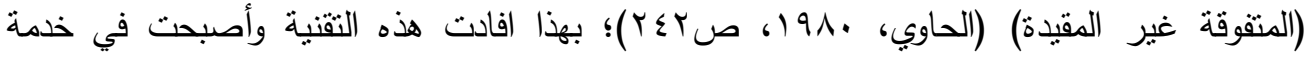

ظلت الجملة الشعرية حافلة بمعطيات هي الأصدق في التعبير عمّا بكن في ذاته والنزول بلغة الثعر إلى منزلة اليومي والمهمل، وليس اللغة التراثية التي أنهكها كثرة الاستعمال مما يفقدها عنصر الأصالة؛ وهذا لا يعني محددات في الموضوع فالكل مناحة أمام الثاعر؛ فنزوله إلى الشارع بكل طبقاته خصوصاً الكلام الشعبي، الأسواق، المقاهي، الشارع، الوظيفة، بائعو الكتب، الأغاني، الكلام الشعبي، الشعر البسيط، ذكربات الحرب، يقول الحطّّب: سأكنس أطفالي، دون رحمة) (الحطّاب، المصدر نفسه، صسابل) أو في نحو قوله: (ماذا أفعل؟ 
العدد الحادي والأربعون

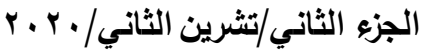

لا أجيد الغناء ...

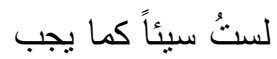

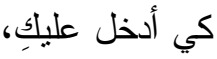

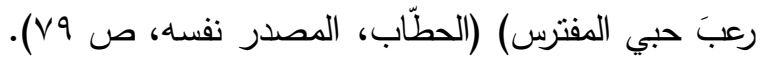

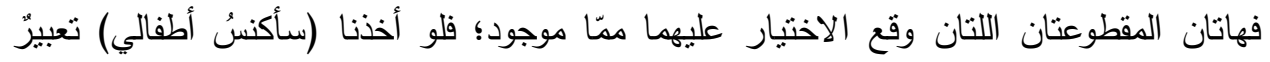

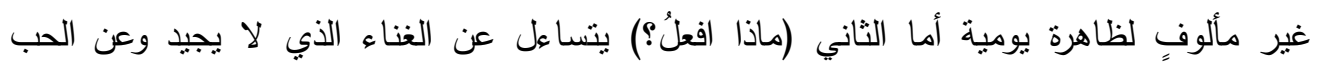
المفترس؛ فالثشاعر استطاع تفعيل النص بأكبر كمية من شعرية اليومي والمهمل.

الاستفهام:

يُعدُ الاستقهام من الأساليب التي لها الإمكانية القصوى في بيت الثعر العربيّ قديمًا وحديثًا؛ فلهُ

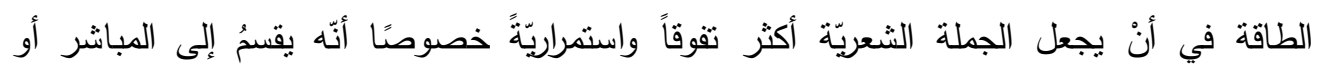

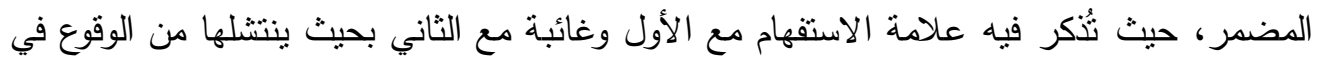
التقريريّة والجاهزيّة التي قد تعاني منها القصبدة. يقول الحطّاب: (أئها الشاعر

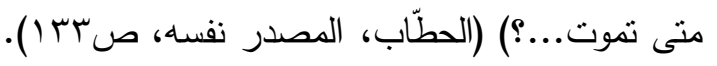
أو في نحو قوله: (كيف سأدخن مساءً مع الهمود الحمر فئر

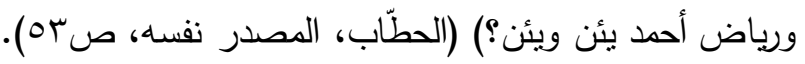

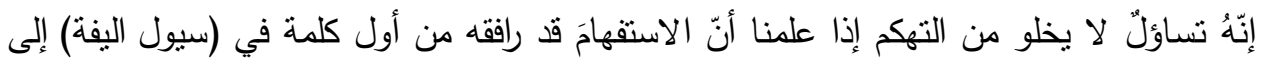

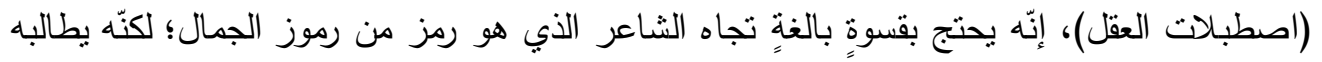
بالتوقف عن ممارسة الحياة وهي صورةٌ قاتمةٌ تجعل من الفنان (رياض أحمد) يُكثر الأنين (الونين)

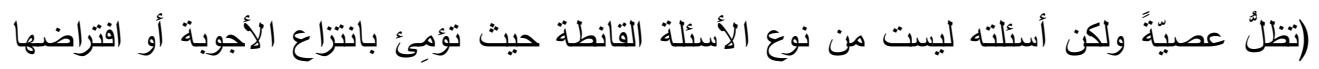

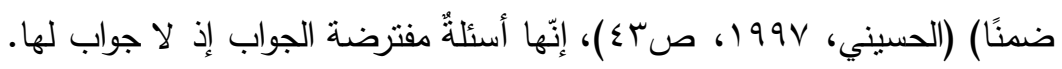
التكرار:

مارس الحطّاب النكرار؛ لما يؤديه من وظيفة بالغة الإيجايّة داخل النص الشعري كما تقول

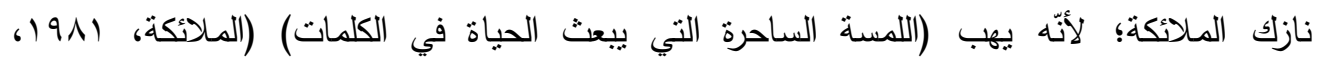

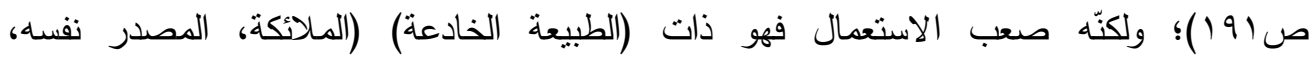
ص (19) قد يقع فيه قليل الخبرة والممارسة بما لا يُحمد عقباهُ. 
العدد الحادي والأربعون

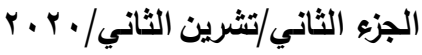

وللتكرار أنواع عدة مثناً: تكرار التلاشي، وتكرار المعنى، وتكرار الصور، وتكرار الإيقاع، وتكرار العبارة، وتكرار الكلمة، وتكرار الرمز، واذي يُهمنا بدرجةٍ أساس كيف استطاع الحطّاب من نوظيفه لصالح نصه الشعريّ، يقول: (السياراتُ تطير

القصوز تطير ... الحدائق نطير المدسات نطير ... النفايات نطير

لكني أحلّقُ في العمق ولا أسقط) (الحطّاب، المصدر السابق، ص. • ع (). نحن هنا أمام جيش من التكرارات المترادفة بين الجماعة والأنا وهو يقيم نوعاً من الثنائيات حرص هل الثاعر غلى إقامته وإيجاده كنوع يُحسب له في خريطة الشعر التسعينيّ. النوع الأول: تطير السيارات / القصور/ الحدائق/ المسدسات/ النفايات/ النوع الثاني: الأنا أحلقُ في العمق.

هذا النوع من البناء الثعري أسهم بشكل كبير في أن يجعلَ الجملة التكرارية خصوصًا الثنائيات (الجماعة والأنا)؛ لتقرزَ في نهاية المطاف السقوط المنتظر، بينما الأنا المحلّة في سماء القصيدة.

كسر التوقع (الضربة):

شاع في قصيدة التسعينات أسلوب كسر التوقع أو الضَّربة كما يسمونهُ عادة ولهُ جذورٌ في القصيدة العربية؛ وإنْ كان يفترق من حيث الاستخدام، فقد كان العرب بطلقونهُ على بيت القصيدة وهو

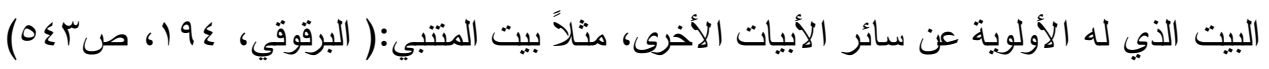

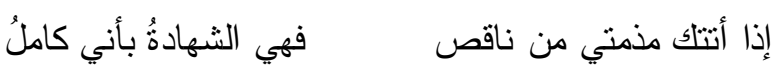
لقد وظّفَ الشعر التسعينيّ هذا الأسلوب بشكلٍ مغايرٍٍ، وإنْ كانا بلتقبان عند الجذور ؛ فقصائدهم تميل إلىى القصر والإيجاز وتكون غالبًا نهايتها كسر التوقع أو ما يُسمّى بالضّربة، يقول الحطّاب:

(هذا الرصاص (اص)

الرصاص الذي يزأر يبحثُ عن رؤوسنا كي يقبلها) (الحطّاب، المصدر السابق، صعء • ()). إنّ الضربة المتحققة في نهاية القصيدة (كي يقبلها)؛ لرغبة الرصاص الذي بزأر، أنهّا مطاردَّةُ

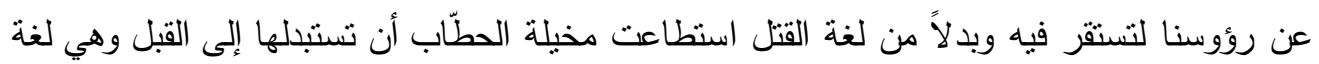
العاشقين التي لن تتنشل الخطاب الشعري الذي ظلَّ سائداً. 
العدد الحادي والأربعون

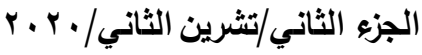

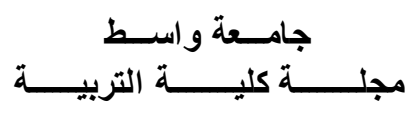

الصورة:

لأعترفُ مقدمًا أنّ الصورة الثعريّة غاية في الجمال؛ لهذا قيل إنّ الشعر بلا صورة كأنّهُ بلا حياة،

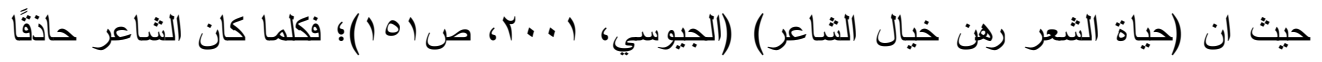
متمكناً من السيطرة على أدواته داخل عمله الشعري كلّما ساهم ذلك في بناء الصورة الشعرية. وقد سبق القول في هذا المجال مقولة الجاحظ بان الثعر (ضربُ من التصوير) (الجاحظ، مصدر سابق، ص.r (1)، مما يجعل الصور غاية في فهم الشعر وتذوقه. وكانت الأدوات المساعدة في نشكيل صورة الخطاب هي كالآتي: التشبيه/ الصورة الكلية/ الومضة/ المفارقة/ الاستعارة.

التشبيه:

لعب التشبيه دوراً كاملاً في تشكل الصورة الشعرية؛ إذ لا يخلو منهُ أبيّ نصٍِ أدبي سواء بذكر الأداة وهو كثيرُ عند الحطّاب، لاسيما كلمة (منل) أو الأداة (الكاف) التي كانت منتعبةً في خلايا النص وأقل منها بعض الثيء الأدوات الأخرى، (إنَّ الصورة التي تقوم على التشبيه تخالف في التي الغالب طبيعة التجربة الشعرية؛ لأنَّ التقاط الثبه بين ظاهرتين مختلفتين يقوم أصلاً على نهج منطقي ينفذ من المقدمات إلى النتائج بالتفكير والإدراك من دون الشعور والمعاناة) (الجيوسي، مصدر سابق،

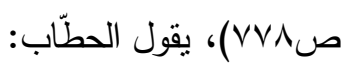

$$
\text { (وكنتُ أضحك) }
$$

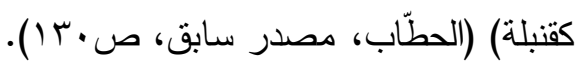

لقد أدت(الكاف) دورها الشعريّ لاسيما الضحك الأصفر الذي يشابه انفجار قنبلة، إنّ التشديد

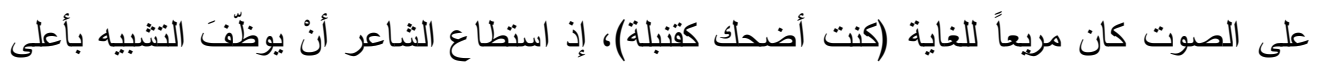
حِرفية ممكنة من إدانة الحرب في كل النواحي، كذلك باقي الأدوات، يقول: (كأنّها عصفورة منقرضنة

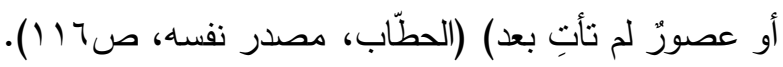

يشتغل النص الثعري بوصف الطفولة المسروقة فهي (منقرضة) و (لم تأتِ بعدُ)، إنّها ولادة قسرية؛ لكنها من زمن الانقراض، إنّ الواقع الحياتي أصبح خيالياً في كلّ شيءٍ يشكله الثاعر؛ إنّهُ أمام معادلة خاسرة على المستوى الحياتي؛ لكنَّهُ أمام الشعر يجد حيوات مغايرة. 
العدد الحادي والأربعون

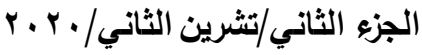

الصورة الكلية:

ظلَّ إيقاع الفكرة يناسب كثيراً الصورة الكليّة؛ فهي تتكئُ على مجموعة من الصور الجزئية لا تتنهي حتى يكتمل المعنى الكليّ للقصيدة وأحياناً تركبُ الموجة الصور الجزئية، وأحياناً أخرى الكلية؛ وهذا راجعُ إلى طبيعة الظرف الذي نعيشهُ قد يكون متقرداً للهُ الأولوية في ذلك ويظلّ عمله عالقاً في

إن طريقة البناء في الكلية (تحمل معها بذور البناء الدرامي) (أبو إصبع، 9V9 1، صVV) ويفترق عن هذا البناء بوساطة المشهد أو المقطع أو التقصيل، فكل نص قائم بذاته.

$$
\begin{aligned}
& \text { يقولُ الحطّاب في قصيدة الأسطوري: } \\
& \text { (غرفتي هجرتها الفئران } \\
& \text { غرفني المرعبة }
\end{aligned}
$$

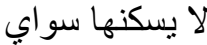

$$
\begin{aligned}
& \text { أنا الأسطوري ألخالد.... }
\end{aligned}
$$

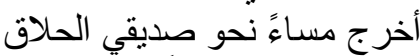

$$
\begin{aligned}
& \text { و الذي لم يحلق شيئًاً } \\
& \text { سوى حياته } \\
& \text { مروراً بصديقي اليوسفي } \\
& \text { و الذي لم يكن يو سيفياً }
\end{aligned}
$$

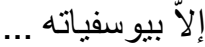

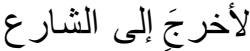

$$
\begin{aligned}
& \text { منتظرا عبور في الى الميع الماشية } \\
& \text { كي أصل غرفتي } \\
& \text { غرفتي التي هجرتها الفئران } \\
& \text { لا يسكنها سواي }
\end{aligned}
$$

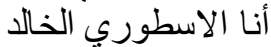

$$
\begin{aligned}
& \text { لم أكن أسطورياً يوماً }
\end{aligned}
$$

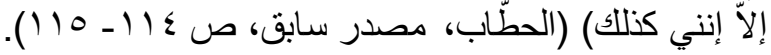

يسرد الحطّّب محطات قصيدته إلى صور خمس أو لقطات من زوايا متعددة، وكل زاوية تصور المشه بصورة مغايرة عن الأخرى، فالأولى (غرفتي هجرتها الفئران)، والثانية (صديقي الحلاق/والذي روني لم يحلق شيئاً/ سوى حياته)، والثالثة (صديقي اليوسفي/ والذي لم يكن يوسيفياً/ إلاّ بيوسفياته)، والرابعة (منتظراً عبور قطيع الماشية/ كي اصل غرفتي)، والخامسة (لم اكن أسطورياً/ يوماً)، وعند تجميع اللقطات سنحصل على الصورة الكلية التي تصور إنساناً عادياً هو (الانا) من خلال يوم واحد في حياته. 
العدد الحادي والأربعون

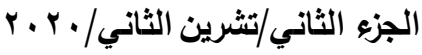

الومضة:

لا شك أنّ الومضة الشعرية تُعدُّ ركناً من الأركان المهمة التي تعتمد عليه ليس في الصورة وحسب؛ وإنما في غاية الضرورة لبقية العناصر الثعرية الأخرى. وقد وجدنا أنّ التنظير للومضة لا طائل من ورائه، وبدلا عن ذلك، الذهاب إلى النص الثعري الذي تعجُ به المجموعات؛ ونتيجة للكثرة، سنختار فيما يخص الصورة مثنلاً، يقول الحطّاب:

$$
\begin{aligned}
& \text { (لست سوى رجل شجاع) } \\
& \text { شجاع وحذر } \\
& \text { كيف أميز حبك }
\end{aligned}
$$

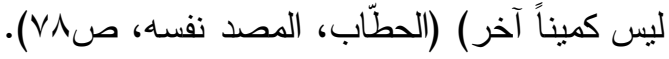

إنّ الصورة نشتغل اشتغالاً عالي الشعرية فهو (شجاع) مكررة، و (حذر)؛ لكنه خوفاً من السقوط الذي ينصب له(كميناً) وبهذا يتحول الحبُّ وهو أسمى شعور إنساني مدعاة من الخوف الذي تصادره

$$
\begin{aligned}
& \text { الصورة. وثمّة ومضة في قوله: } \\
& \text { (أيامكم طاووس } \\
& \text { وأيامنا غراب } \\
& \text { أحلامكم مباركة }
\end{aligned}
$$$$
\text { وأحلامنا جحيم) (الحطّاب، المصدر نفسه، ص صدور). }
$$

إن الومضة شديدة الحرص في تصوير الجانبين بالاعتماد على (الأيام/ الأحلام) تاركاً الغوص في دهاليز الوضوح؛ فأيام الآخر (طاووس)، في حين الأنا(غراب) والفرق لا يحناج كثيراً من السواد المغلف بالجحيم، إنّ الصورة الشعريّة غاية في تجربة الحطّاب، وإنْ كنا قد ركّزنا على أهم صور الاشتغال الصوري، وحاولنا إبرازها جليةً واضحة في الخطاب الشعري.

المفارقة:

ظلت المفارقة مساحةً خضراء في عيون الشعراء، عادة ما يلجأ إليها للإغتراف من كنوزها الدفينة

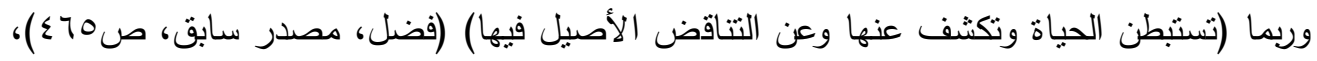

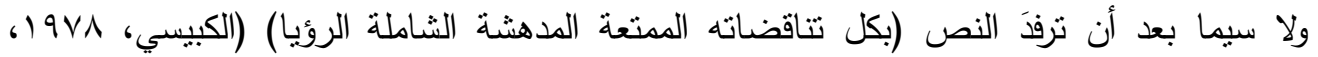
ص99 (19)، لذلك حصد ما بذره الثاعر فرج الحطّاب، يقول:

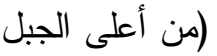


العدد الحادي والأربعون

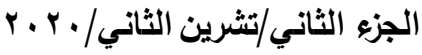

واترك سيزيف للحجر) (الحطّاب، مصدر سابق، ص ؟ ؟). تتشكل الصورة اعتماداً على المفارقة التي تبرزهُ ثنائية التضاد بين(الجبل) و (الهاوية)، وبين (القمة) و (الحجر)، إنّ الصورة غارقةٌ في الثنائيات من خلال فضح الواقع المأساوي الذي تشيطر عليه صورتان، الأولى قد أشرنا إليها، والأخرى هي صورة البطل الأسطوري (وترك سيزيف / للحجر)؛ وهنا تكمن المفارقة بأن ينرك أمام سلطةٍ قاهرة جبارة في كل ما يحيطها. ويقول الحطّاب: (يصر على تعقيم أسنانه

ولا يستعملها) (الحطّاب، مصدر نفسه، صع ـ ( ). لعلّ المفارقة صاحبة الحظ الأكبر لاسيما أنّ الصورة اشتغلت بهدوء صامت فالذي يحاول بجهٍ مضني على(الإصرار) نجده في نهاية الأمر لا يجيد شيئًا سوى التخلي (ولا يستعملها)؛ إنها مفارقة صارخة وظّقها الشاعر بإمكانية قصوى.

الاستعارة:

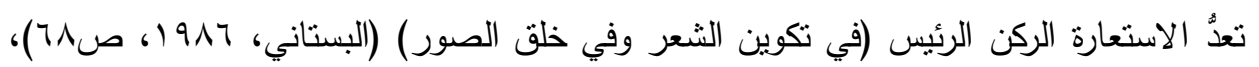
فضلاً عمّا نقوم به من حيث التقربب بين المنباعدين، فتصبح بذلك اللمحة الواجبة العذوبة لا يستغني

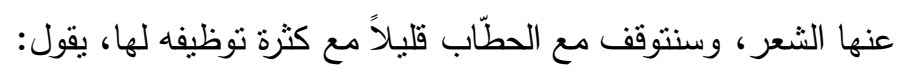

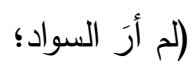

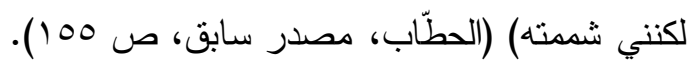
إن القصيدة حازت على الصورة الثعرية في أقل المفردات وأكثر المعاني سطوعاً فقد استعار

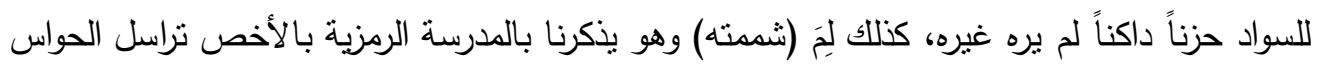

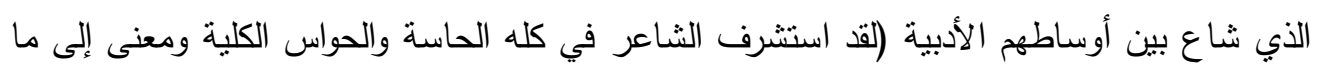
وراء الحاسة الواحدة القفلة العمياء) (الحاوي، مصدر سابق، صهَr)، يقول الحطّّب:

$$
\text { (الغيوم التي تمـأ رأسي }
$$

سوف تمطر أفكاراً عظيمة 
العدد الحادي والأربعون

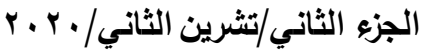

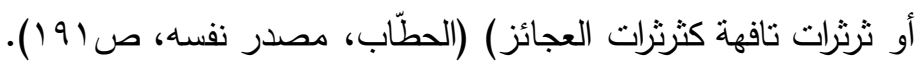

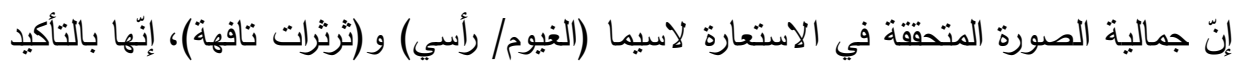

الغيوم ليست إلاّ حزناً أو أفكاراً أو هذيانات يجعلنا نستبعد كل البعد تهمة التقاهة عنها؛

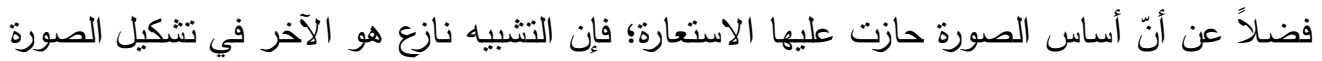

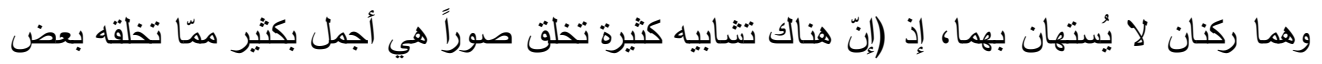

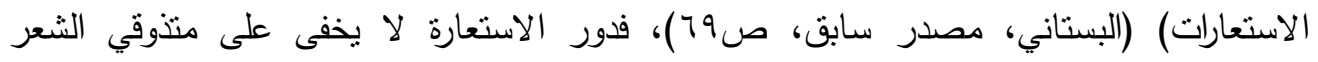
ودارسيه.

ويجب الإثشارة هنا إلى أنتّا استثتينا دراسة الايقاع المألوف؛ ذلك أنّ شعرية القصيدة تشتغل لديه

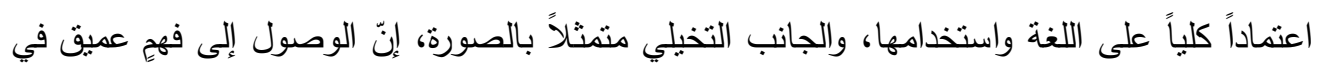
دراسة الإيقاع بحاجة ماسة إلى قناعة خالصة في قصبدة النثر وهذا جلُّ ما نبغيه.

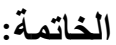

ختاماً انتهيت إلى النتائج الآتية: ا - ظلت قصيدة النثر غائمة في بدايتها إلا إنّها نشطت ابتداء من ستينات القرن العشرين إلى الى يومنا الحالي خصوصاً نبلها الجوائز العربية وأضحت معترفاً بها في الوسط الأدبي.

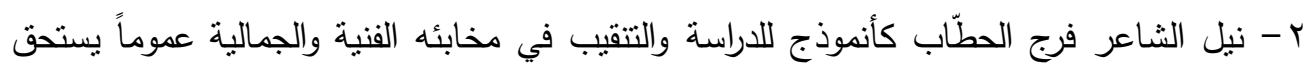
بما بمنلك من أدوات شعرية. r- توصل البحث في جل ما توصل إليه بأنّ الثاعر يختلف عن باقي الثعراء في (سيول أليفة)

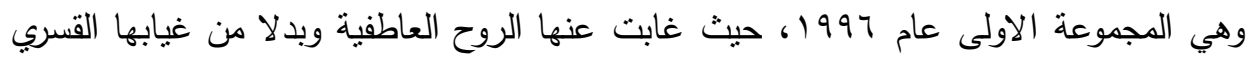
وجدنا الظروف العاتية كالحروب الطويلة والحصار وما شابه ذللك. ع - سيطرت ألفاظ عامية معينة على مجمل حياته الثعرية وكذلك ألفاظ عامية رغم انهّا قليلة الكثرة؛

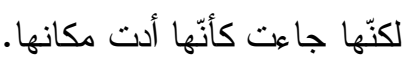
ه - كانت الفنية وهي الاخير في ترنبه من حيث التتاول وقد آثرنا اللغة الثعرية لما لها من اساليب معينة لاى الخطاب كالومضة والمهمل، والاستقهام، وكسر التوقع، والتكرار .

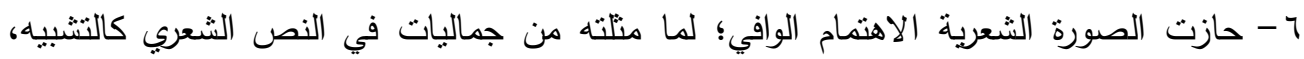

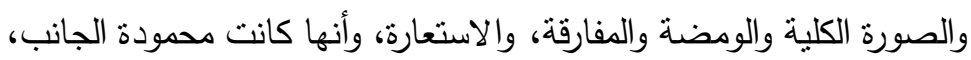


العدد الحادي والأربعون

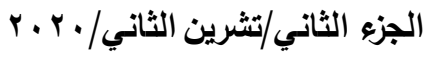

V - بقيت الموسيقى عنصرا مستقبلاً علّه تسمح به الأيام فما زال الجمهور عامة لم يقنع بالصورة الموسيقية وظلت دراسات أبي ديب واخرين لم ترتقِ لأن تقدم البديل.

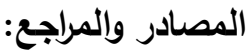

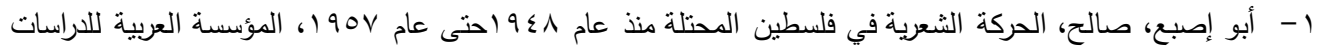

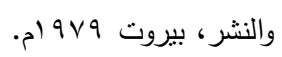

r - أدونيس، صدمة الحداثة، دار العودة، بيروت،

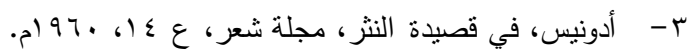

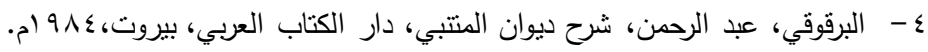

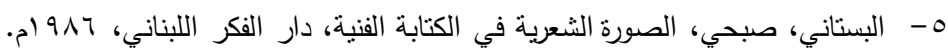

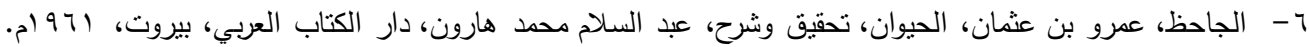

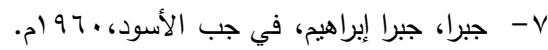

^- الجيزاني، زاهر، وكاظم، سلام، الموجة الجديدة نماذج من الثعر العراقي الحديث، دار الشؤون النقافية العامة، بغداد،

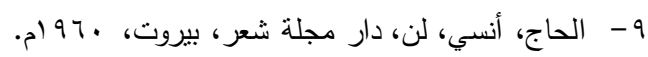

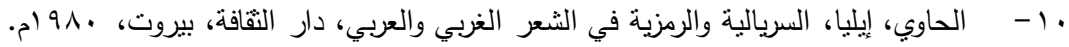

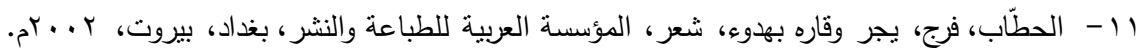

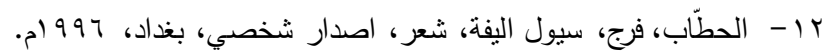

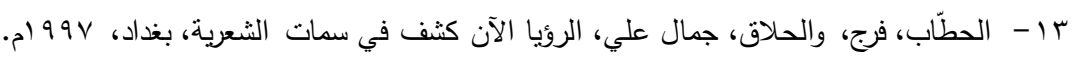

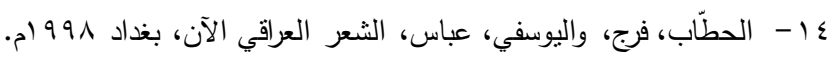

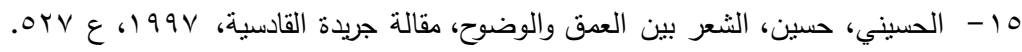

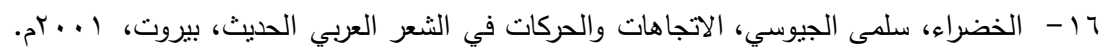
IV

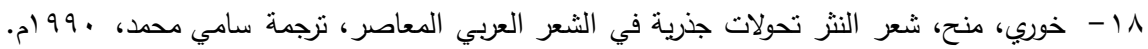

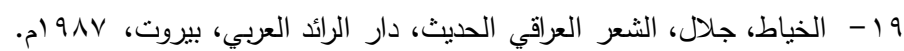

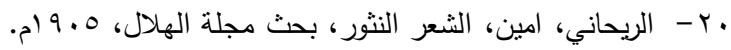

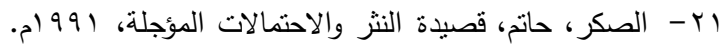

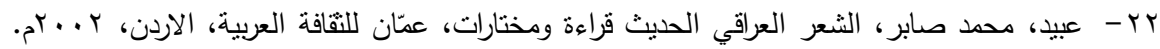

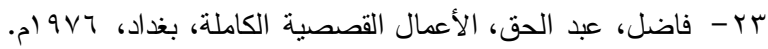

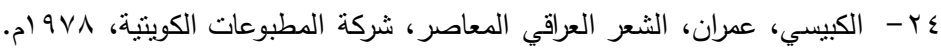

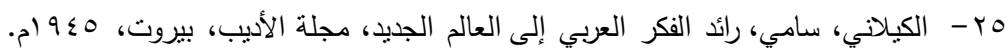

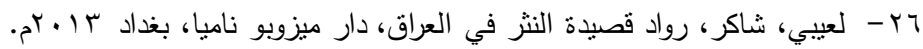

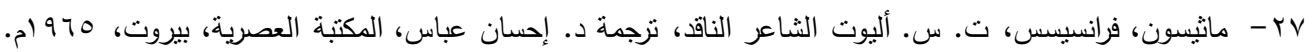


العدد الحادي والأبعون

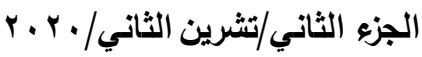

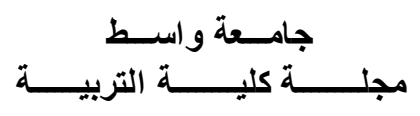

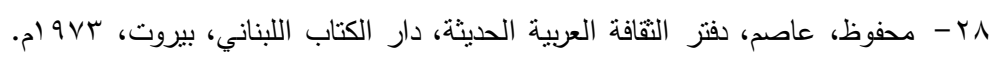

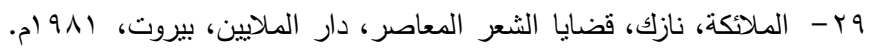

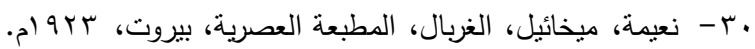

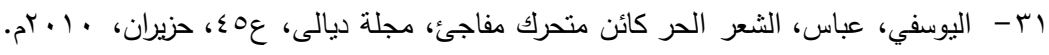

